\title{
Optimized Fuzzy Logic Solar Module MPPT Controller Modelling using PSO
}

\author{
Pankaj Kumar Gupta ${ }^{1}$, \\ ${ }^{1}$ Assistant Professor, ABES Engineering College, Ghaziabad, India
}

\begin{abstract}
In this paper we have focused on MPPT based solar system performance enhancement by use of fuzzy logic controller's designs optimized by particle swarm optimization (PSO). We have described about different latest A.I. techniques that has been hybrid with fuzzy logic for improving PV array based solar plants performance in recent time. The artificial intelligence technique applied in this work is the Particle Swarm Optimization (PSO) algorithm and is used to optimize the membership functions for maximum power point tracking rule set of the FLC. By using PSO algorithm, the optimized FLC is able to maximize energy to the system loads while also maintaining a higher stability and speed as compared to $\mathrm{P} \& \mathrm{O}$ based MPPT algorithm.
\end{abstract}

Key words: Fuzzy Logic Controller, MPPT, PSO, P\&O, Solar System.

\section{INTRODUCTION}

In spite of the course impacts of the money related emergency that have influenced each part, in differing degree and geography, the interest in renewable energy keeps developing with a maintainable pattern. By new report of the UNEP (United Nation Environment Program), the interest in renewable energy rose 5\% in 2008 demonstrating certainly the foundation of new strategies for electric power generation and affirms that this area speaks to now a standard energy investment [1]. The atmosphere of the great soundness of renewable energy is the product of the cooperation of the legislative and societal engagement towards substantial activities to moderate environmental change by lessening Green House Gasses (GHG), decreasing their reliance on fossil fuel supply and making energy security a key need. Surely, the current monetary and sparing emergency might have backed off the interest on the fossil fuel energy and driven down costs. Yet, the world conclusion is still persuaded [2], that is just a brief delay. It appears that there is an inactive danger structure energy emergency, and will constitute a decent stimulus for the development of the renewable energy period.

To face this threat from resources depletion, solar energy is recognized as a robust alternative to unsustainable energy use in developed and developing countries. During the last two decades, the rhythm of the implementation of solar farm using PhotoVoltaic (PV) panels or Concentrated Solar Power (CSP) technologies has accelerated in the countries situated in the solar energy belt, despite their prohibitive costs. By International Energy Agency (IEA) solar electricity will grow up to $20-25 \%$ by 2050 . The IEA has likewise anticipated that, by 2050, the PV and CSP frameworks will have the capacity to produce $9000 \mathrm{TWh}$ of power and diminish the yearly $\mathrm{CO} 2$ emanations by right around 6 billion tones [3].

Solar energy asset appraisal and site suitability for huge PV ranches executions is influenced by various elements which can be characterized in three primary classes: Technical, Economical and Environmental. These elements rely on upon the topographical area, biophysical characteristics and socio-economical foundation of the nation under study. Notice that the dust and sand hazard components are just particular to the locale and may not make a difference for different nations with mild atmosphere. The suitability of the area of a PV homestead is resolved in view of the blend with various weights of the considerable number of elements recorded previously. The most insolated regions are inclined to high suitability. Vicinity to streets stays away from extra cost of base development and important harm to the situations. Lands that have insignificant quality because of past use and current conditions ought to be assessed for potential PV ranches organization. PV ranches are especially suitable where the association with the current electric framework is easy [5]. The game plan to execute PV ranches in close closeness to the current lattice and burdens shaft decrease essentially transmission misfortunes. Substantial scale PV ranches require level landscape or genuinely soak slant that is confronting south with not exactly a 5\% reviewed incline.

\section{RELATED WORK}

This work presented by Yassine Charabi and Adel Gastli (2011), [3] some preparatory results from an exploration study led on solar energy asset evaluation in Oman. GISbased spatial multi-criteria assessment approach, regarding the FLOWA module was utilized to survey the area suitability for huge PV ranches execution in Oman. The instrument utilized applies fuzzy quantifiers inside ArcGIS environment permitting the incorporation of a multi-criteria choice investigation. Land suitability examination for substantial PV ranches execution was completed for the contextual investigation of Oman. The overlay results acquired from the investigation of the resultant maps demonstrated that $0.5 \%$ of the aggregate area zone show a high suitability level. Distinctive PV innovations were considered for execution. It was found that the CPV innovation gives high specialized potential to actualizing 
huge solar plants. Truth be told, if all exceptionally suitable area is totally abused for CPV execution, it can create very nearly 45.5 times the present aggregate force request in Oman. The device utilized as a part of this investigation is the Fuzzy Logic Ordered Weight Averaging (FLOWA) module created by Boroushaki and Malczewski that was incorporated inside ESRI Arc Map 9.3.

G. Balasubramanian and S. Singaravelu [11] have presented a Fuzzy Logic Controller for Maximum Power Point Tracking (MPPT) in photovoltaic system. A simple and precise strategy for displaying photovoltaic clusters is proposed. The model and fuzzy based control procedures are joined to shape wise controllers that are more precise and robust. The model based controller is outlined such that the reference signal for PWM generator of the converter can be conformed to accomplish most extreme force era from the photo voltaic system. The proposed fuzzy rationale controller shows better exhibitions contrasted with the $\mathrm{P} \& \mathrm{O}$ and PI MPPT based methodology. A MATLAB based displaying and reproduction plan alongside MPPT and fuzzy rationale controller is proposed which are suitable for concentrating on the $I-V$ and $P-V$ qualities of a PV exhibit under a non-uniform light and distinctive temperature. The model has been tentatively accepted.

GorkaLanderas , José Javier López, Ozgur Kisi, and Jalal Shiri (2012), [4] according to them surface incoming solar radiation is a key variable for many agricultural, meteorological and solar energy conversion related applications. Without the required meteorological sensors for the recognition of worldwide solar radiation it is important to gauge this variable. Temperature based demonstrating methods are accounted for in this study for assessing day by day using so as to approach solar radiation Gene Expression Programming (GEP) surprisingly, and other counterfeit consciousness models, for example, Artificial Neural Networks (ANNs), and Adaptive NeuroFuzzy Inference System (ANFIS). An examination was additionally made among these methods and customary temperature based worldwide solar radiation estimation mathematical statements [13]. Root mean square error (RMSE), mean absolute error (MAE) RMSE-based aptitude score (SSRMSE), MAE-based expertise score (SSMAE) and $r^{2}$ foundation of Nash and Sutcliffe criteria were utilized to survey the models' exhibitions. An ANN (a four-data multilayer perceptron with 10 neurons in the concealed layer) introduced the best execution among the studied models (2.93 $\mathrm{MJ} \mathrm{m}^{-2} \mathrm{~d}^{-1}$ of RMSE). The capacity of GEP way to deal with model worldwide solar based radiation in light of day by day climatic variables was observed to be palatable.

\section{METHODOLOGY}

In recent years, because of global warming and the rise in crude oil price, countries worldwide have begun to invest heavily in research and development related to renewable energy sources. Among renewable energy generation systems, solar power generation has received the most attention; from small-scale applications (e.g., energy provision to consumer electronics) to large-scale operations (e.g., solar power plants) $[8,9]$, the scope of solar power applications is broad. However, because the energy conversion efficiency of photovoltaic (PV) generation system (PGS) is low and the cost of solar power generation is higher than that of thermal power generation or nuclear generation, determining how to acquire maximum power from a PGS has become an essential topic. The characteristic curves of a solar cell are nonlinear and depend on the irradiance level and ambient temperature, resulting in a unique current-voltage (I-V) curve. Consequently, the operating point (OP) of a PGS must be adjusted to the extent in which the maximum efficiency of the solar cells can be achieved, and this technique is called maximum power point tracking (MPPT) [14].

The Perturb and Observe ( $\mathrm{P} \& \mathrm{O})$ method is the most common MPPT approach applied in commercial PGSs [15]. This method determines the system control commands according to the difference in the power output between the current system state and previous system state. Consequently, determining the perturbation step applied to a system is an essential topic. At the point when a considerable annoyance step is used by a framework, the time required for the framework to track the maximum power point (MPP) and accomplish an unfaltering state is short, yet the measure of force misfortune brought about by the bother is high. By complexity, a little annoyance step can reduce the force misfortune brought about by the bother however diminish the following rate of the framework. This marvel is for the most part known as the exchange off between following speed and following exactness [16]. By and large, MPPT strategies that apply the altered step size strategy are influenced by the exchange off. Thusly, scientists have proposed various variable step size MPPT strategies to ease this difficulty. The center idea of variable step size MPPT is that, when the OP of a framework is far off from the MPP, a considerable annoyance step is acquainted with the framework control, along these lines expanding the following rate of the framework. Then again, when the OP approximates the MPP, a little irritation step is acquainted with the framework control to enhance the adequacy of the framework in accomplishing an enduring state [17]. The variable step MPPT strategies specified in past concentrates for the most part decide the irritation venture as per the OP in the power-voltage $(\mathrm{P}-\mathrm{V})$ bend of sunlight based cells. In any case, the trademark bends of sun based cells can change as indicated by the working environment; in this manner, deciding a bother step size appropriate to a wide range of working condition is an essential subject with respect to variable step MPPT. Alternatively, fuzzy logic controller (FLC)-based techniques can be applied to nonlinear systems. Moreover, such techniques do not require accurate system parameters or complex mathematics models to achieve superior control performance [18]. Therefore, FLC-based MPPT methods have become a worthy research topic.

\section{PROPOSED WORK}

In DAPSO2, if there were many particles far away from the global best position, then the velocities should be given 
a larger value. If there were many particles near from the global best position, then the velocities should be given a smaller value. DAPSO1 only adjusts the velocity of the certain particle, but in DAPSO2, the velocities of all particles are adjusted together [19].

The general flow of DAPSOs and the flowchart of DAPSO are shown as follows.

Step 1. Initialization of a population of particles with random positions and velocities

Step 2.Evaluation of particles.

Step 3. Calculate the distance from each particle to the global best position and save the farthest distance in the memory.

Step 4. Adjust particle's velocity according to its distance from itself to the global best position.

Step 5. Update particle's position by the adjusted velocity.

Step 6. Repeat Step.2 Step.5 until termination criteria are met.

To improve the flexibility in the error function to be minimized, so that the desired level of Pmax may be specified, the error function has been considered as fitness function in many literatures [10]. The error fitness to be minimized using the evolutionary algorithms. In this paper, a novel disorder wellness capacity has been received keeping in mind the end goal to accomplish higher stop band weakening and to have better control on the move width.

\section{RESULT AND DISCUSSION PV array Design}

From the theory of semiconductors and photovoltaic, following are the basic equations that mathematically describe the current-voltage relationship of the PV module.

(i) The output current of PV module is given as:

$$
I=N p I p h-N p I s\left[\exp \frac{q(V+I R s)}{N s k T A}-1\right]
$$

where, Iph is the light-generated current or photocurrent; Is is the module saturation current; $\mathrm{q}$ is the electron charge $\left(1.6 \times 10^{-19} \mathrm{C}\right) ; \mathrm{k}$ is the Boltzmann constant $\left(1.38 \times 10^{-23} \mathrm{~J} / \mathrm{K}\right) ; \mathrm{T}$ is the cell working temperature; $\mathrm{A}$ is the ideal factor of cell dependent on PV technology; Rsh is the shunt resistance; Rs is the series resistance; Ns is the number of cells connected in series and $\mathrm{Np}$ is the number of cells connected in parallel. (ii) The module [12] photocurrent depends linearly on the solar irradiation and is also influenced by the temperature according to the following equation:

$$
\mathrm{Iph}=[\mathrm{Isc}+\mathrm{Ki}(\mathrm{T}-\mathrm{Tr})] \lambda
$$

where, Isc is the cell short-circuit current at a $251 \mathrm{C}$ and $1 \mathrm{~kW} / \mathrm{m}^{2}$; $\mathrm{Ki}$ is the cell short-circuit current temperature coefficient [6]; $\operatorname{Tr}$ is the cell reference temperature and $\lambda$ is the solar irradiance level in $\mathrm{kW} / \mathrm{m}^{2}$

(iii) The module saturation current varies with the cell temperature, which is given by:

$$
\operatorname{Is}=\operatorname{Irs}\left(\frac{T}{\operatorname{Tr}}\right)^{3} \exp \left[q \operatorname{Eg} \frac{1 / \operatorname{Tr}-1 / T}{k A}\right]
$$

where, Irs is the reverse saturation current at a reference temperature and solar radiation; Eg is the band-gap energy of the semiconductor used in the cell [7].

(iv) The reverse saturation current of module, at reference temperature is given by:

$$
\text { Irs }=\frac{\text { Isc }}{\exp \left[\frac{\operatorname{dVoc}}{N \mathrm{~N} k \mathrm{KAT}}\right]-1}
$$

where, Voc is the PV open-circuit voltage at the reference temperature.

Using above equation PV array is designed using simulink as shown in figure 1:

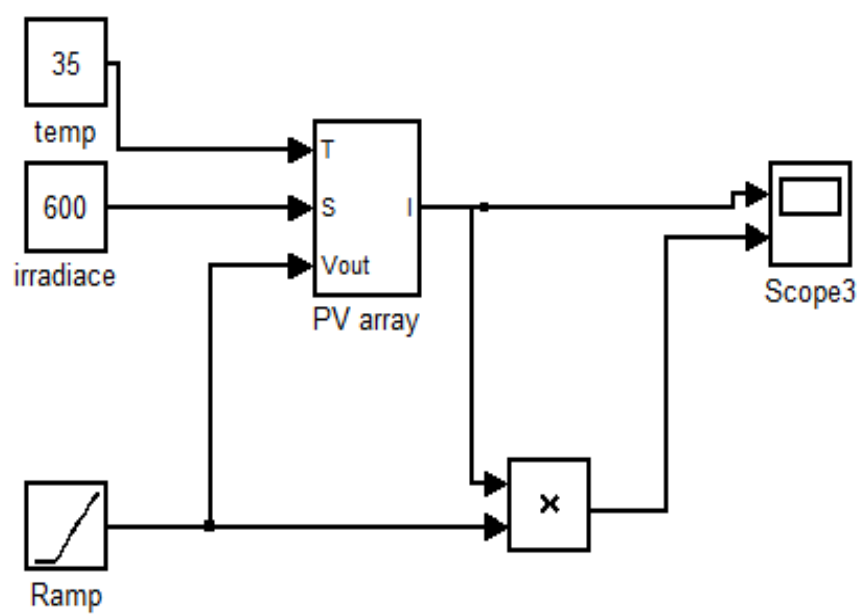

Figure 1: Simulink Model For PV array subsystem.

In the figure 1 Ramp signal is given to Vout and irradiance in $\mathrm{W} / \mathrm{m}^{2}$ is given as S and temp (temperature) is given at input $\mathrm{T}$. The internal connection diagram for the $\mathrm{PV}$ array sub-system is shown below in figure 2 :

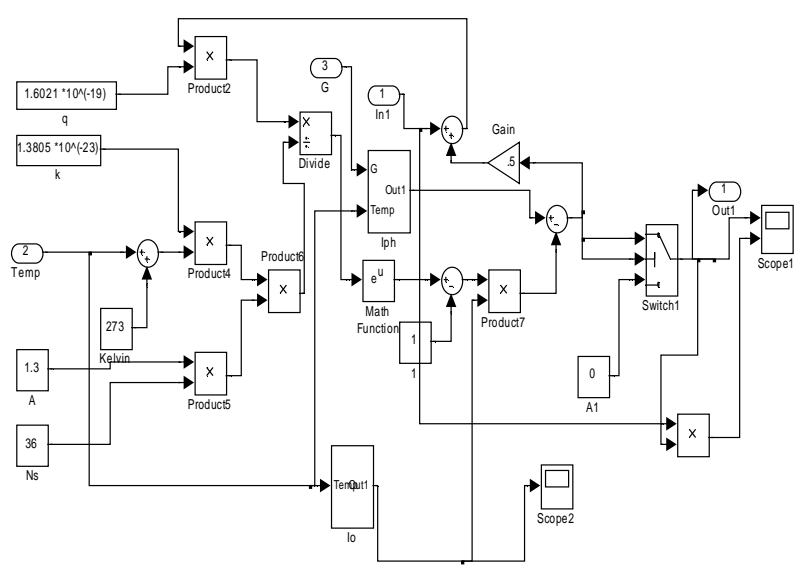

Figure 2: Internal Model of PV array subsystem. 
The specification of PV array is given below:

Sref : $($ Reference Irradiance $)=1000 \mathrm{~W} / \mathrm{m}^{2}$

Tref: (Reference Temperature) $=25^{\circ} \mathrm{C}$

Voc $($ open circuit voltage $)=19 \mathrm{~V}$

Isc(Short circuit current) $=2.3 \mathrm{~A}$

$\mathrm{Vm}($ Voltage at Maximum power at standard $\mathrm{S}$ and $\mathrm{T})=$ $16 \mathrm{~V}$

Im (Current at Maximum power at standard $\mathrm{S}$ and $\mathrm{T})=1.3 \mathrm{~A}$

The Ivs $\mathrm{V}$ and $\mathrm{P}$ vs $\mathrm{V}$ characteristics of above PV array model are shown at standard $\mathrm{S}$ and $\mathrm{T}$.

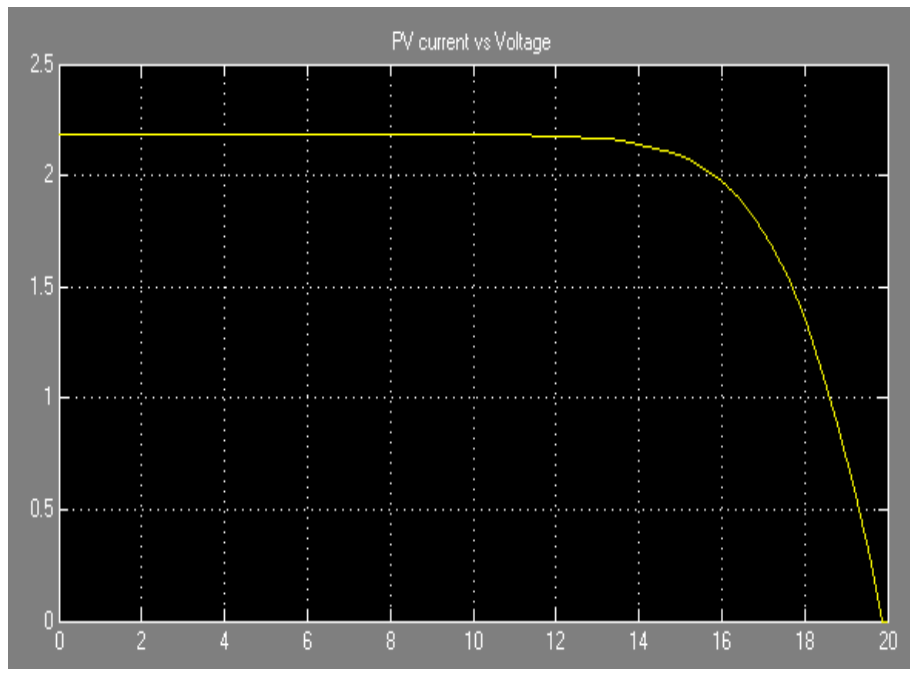

Figure 3: PV Array Current vsVoltage Characteristics.

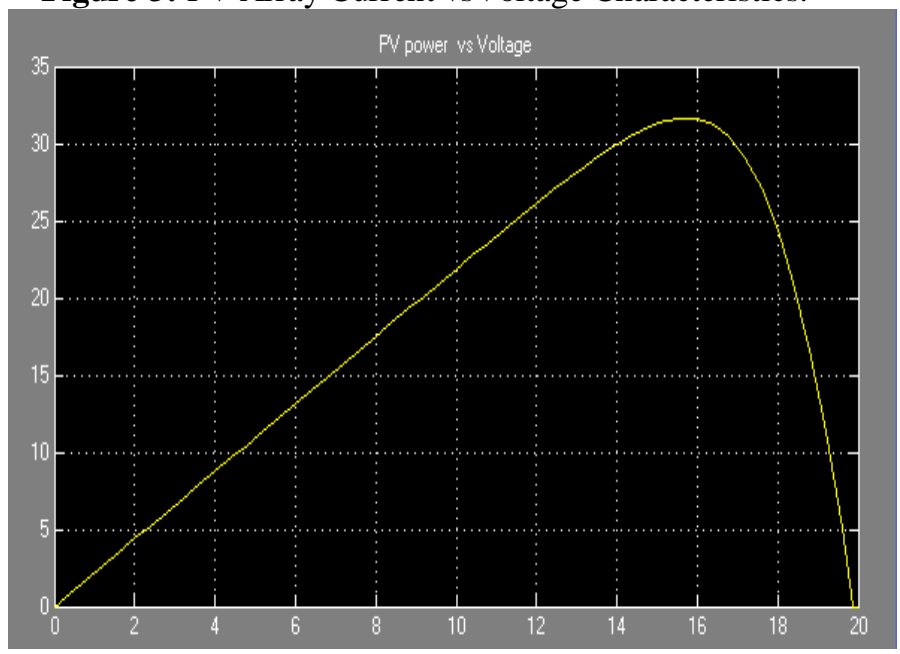

Figure 4: PV Array Power vs. Voltage Characteristics.

Figure 3 is the current vs voltage curve for the PV array model design equation as shown in figure 2.Initially in figure 3 the current is approx. 2.3 A and as the PV output voltage increases due to open circuit conditions and at the last point current terminates to zero at voltage $20 \mathrm{~V}$. Since the $\mathrm{Vm}=16 \mathrm{~V}$ hence we can see that in figure 4 peak occurs slightly near the $16 \mathrm{~V}$ and in figure three we can observe that current at $\mathrm{V}>16 \mathrm{~V}$ vicinity is 1.3 Aapprox. which is also closed to Im. Current is also reaches to zero at voltage near $20 \mathrm{~V}$ i.eaprox equals to Voc $=19 \mathrm{~V}$. The short circuit curren in figure three is equal to maximum current $\mathrm{I}=2.3 \mathrm{~A}$ (approx). Thus above points justifies that the PV array simulink model is performing properly to produce respective voltage and current of PV module.

\section{MPPT controller}

The most commonly used MPPT algorithm is $\mathrm{P} \& \mathrm{O}$ method. This algorithm uses simple feedback arrangement and little measured parameters. In this approach, the module voltage is periodically given a perturbation and the corresponding output power is compared with that at the previous perturbing cycle. In this algorithm a slight perturbation is introduce to the system. This perturbation causes the power of the solar module various. If the power increases due to the perturbation then the perturbation is continued in the same direction. After the peak power is reached the power at the MPP is zero and next instant decreases and hence after that the perturbation reverses as shown in Figure 5.

When the stable condition is arrived the algorithm oscillates around the peak power point. In order to maintain the power variation small the perturbation size is remain very small. The technique is advanced in such a style that it sets a reference voltage of the module corresponding to the peak voltage of the module. A PI controller then acts to transfer the operating point of the module to that particular voltage level. It is observed some power loss due to this perturbation also the fails to track the maximum power under fast changing atmospheric conditions. But remain this technique is very popular and simple.

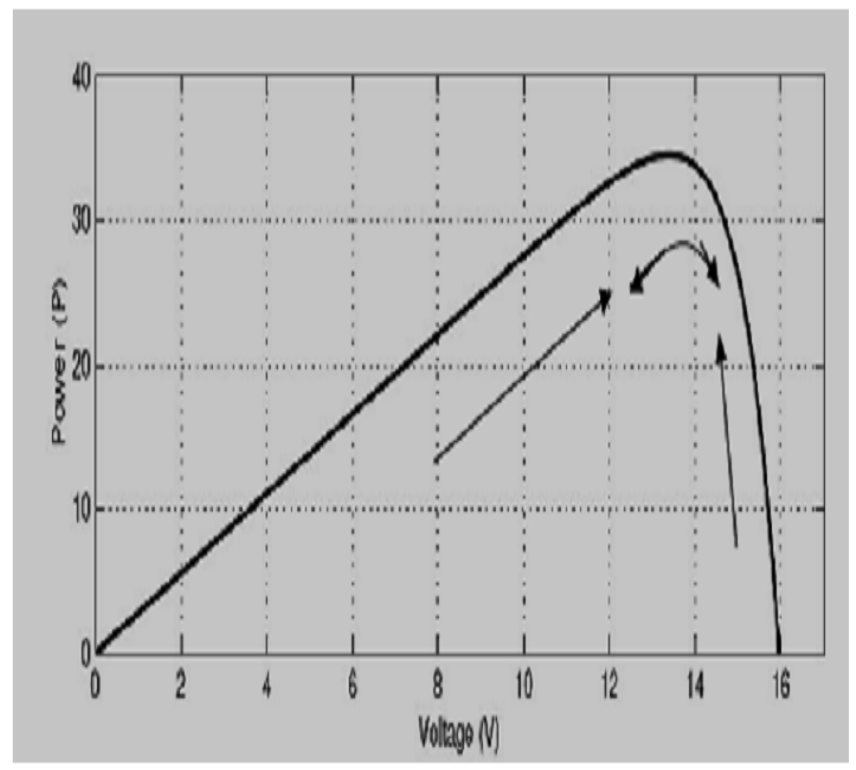

Figure 5: Graph Power versus Voltage for Perturb and Observe Algorithm.

In figure 6 can observe that the fuzzy controller helps to maintain the power of PV array at desired maximum power point for respective irradiance and temp but the Pout is reduced as compared to MPPT controller without using fuzzy. As the irradiance and temperature is varied the MPPT 
regulates the duty cycle at value where we can get $\mathrm{V}$ and I atdefinite point that can produce maximum power. But due to frequent perturbation there are large amount of ripple at the PV array output these ripples are reduced due to regulation of converters and use of filters at the input and output end of converter. Hence it can be concluded that the fuzzy controller and DC-DC converter can help to operate the PV array at maximum power point with significant reduction in voltage and current signal fluctuations.

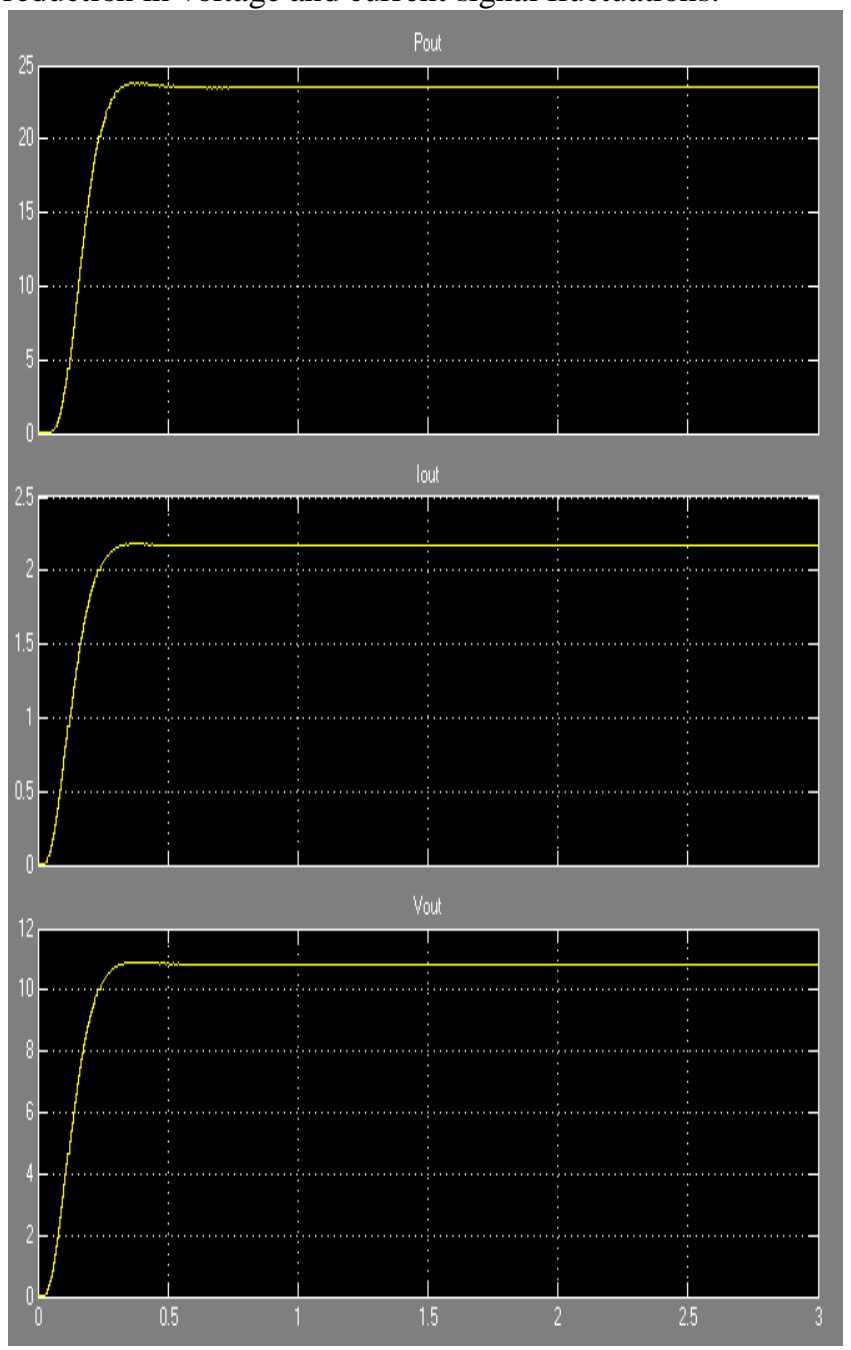

Figure 6: PV array with fuzzy controller and Buck converter input power, current and voltage

\section{CONCLUSION}

In latest time renewable energy sources are gradually becoming very important source of energy. In comparison to all the renewable sources of energy the solar power is most suitable due to its property of least carbon emissions. The output power of a solar photo voltaic cells depends on the sunlight exposure, irradiation intensity and the environmental temperature. This work considers the case of obtaining maximum power from photovoltaic cells based array for power system usage. The objective is consideration of a design of power system that fulfils the requirement of stable and fast maximum power point tracking (MPPT) controller. We have investigated different literature based on solar power MPPT controller fuzzy based approaches which have fabricated MPPT controller using perturb and observe (P\&O) method the incremental conductance method, constant voltage method and short-circuit current method.

\section{References:}

[1] Welch RL, Venayagamoorthy GK. Energy dispatch fuzzy controller for a grid independent photo voltaic system. Energy Convers Manag 2010;51:928-37.

[2] Lee AHI, Chen HH, Kang HY. A model to analyze strategic products for photo voltaic silicon thin-film solar cell power industry. Renew Sustain Energy Rev 2011;15:1271-83.

https://doi.org/10.1016/j.rser.2010.10.008

[3] Charabi Y, Gastli A. PV site suitability analysis using GIS- based spatial fuzzy multi-criteria evaluation. Renew Energy 2011; 36: 2554-61.

[4] Landeras G, López JJ, Kisi O, Shiri J. Comparison of Gene Expression Programming with neuro-fuzzy and neural network computing techniques in estimating daily incoming solar radiation in the Basque Country (Northern Spain). Energy Convers Manag 2012; 62 : 1-13.

[5] Chen SX, Gooi HB, Wang MQ. Solar radiation forecast based on fuzzy logic and neural networks. Renew Energy 2013; 60:195-201.

[6] Ramedani Z, Omid M, Keyhani A, Khoshnevisan B, Saboohi H. A comparative study between fuzzy linear regression and support vector regression for global solar radiation prediction in Iran. Sol Energy 2014;109:135-43. https://doi.org/10.1016/j.solener.2014.08.023

[7] Kharb RK, Shimi SL, Chatterji S, Ansari MF. Modeling of solar PV module and maximum power point tracking using ANFIS. Renew Sustain Energy Rev 2014; 33 : 60212.

[8] Kisi O. Modeling solar radiation of Mediterranean region in Turkey by using fuzzy genetic approach. Energy 2014;64:429-36.

[9] Chekired F, Mellit A, Kalogirou S A, Larbes C. Intelligent maximum power point trackers for photo voltaic applications using FPGA chip: a comparative study. Sol Energy 2014; 101:83-99.

[10] Arulmurugan R, Suthanthiravanitha N. Model and design of a fuzzy-based Hopfield NN tracking controller for standalone PV applications. Electro Power Syst Res2015;120:184-93.

https://doi.org/10.1016/j.epsr.2014.05.007

[11] G. Balasubramanianet. al., "Fuzzy logic controller for the maximum power point tracking in photovoltaic system" International Journal of Computer Applications (0975 8887) Volume 41- No.12, March 2012.

[12] AreenAbdallahAllataifeh, Khaled Bataineh, and Mohammad Al-Khedher, "Maximum Power Point Tracking Using Fuzzy Logic Controller under Partial Conditions", Smart Grid and Renewable Energy, 2015, 6, 1-13

[13] Po-Chen Cheng et. al., "Optimization of a FuzzyLogic-Control-Based MPPT Algorithm Using the Particle Swarm Optimization Technique", Energies 2015, 8, 53385360; doi:10.3390/en8065338. 
Pankaj Kumar Gupta, International Journal of Emerging Trends in Engineering Research, 8(8), August 2020, 4220 - 4225

[14] Anurag, R. Sharma, " Load Forecasting by using ANFIS", International Journal of Research and Development in Applied Science and Engineering, Volume 20, Issue 1, 2020.

[15] R. Sharma, Anurag, " Detect Skin Defects by Modern Image Segmentation Approach, Volume 20, Issue 1, 2020.

[16] Anurag, R. Sharma, " Modern Trends on Image Segmentation for Data Analysis- A Review", International Journal of Research and Development in Applied Science and Engineering, Volume 20, Issue 1, 2020.

https://doi.org/10.30534/ijatcse/2019/80862019

[17] R. Sharma, Anurag, " Load Forecasting using ANFIS A Review", International Journal of Research and Development in Applied Science and Engineering, Volume 20, Issue 1, 2020.

[18] Young Soo Janget. al., "Development of the costeffective, miniaturized vein imaging system withenhanced noise reduction", International Journal of Advanced Trends in Computer Science and Engineering, Volume 8, No.6, November - December 2019.

[19] Irma T. Plata1,et. al., "Development and Testing of Embedded System for Smart Detection andRecognition of Witches' Broom Disease on Cassava Plants using EnhancedViola-Jones and Template Matching Algorithm", International Journal of Advanced Trends in Computer Science and Engineering, Volume 8, No.6, Volume 8, No.5, September - October 2019. 